\title{
Impact of Iron Doping on Structural and Optical Properties of Titanium dioxide
}

\author{
Asfandyar Imtiaz ${ }^{1}$, Mashhood Ahmad ${ }^{1}$, Attaullah Shah ${ }^{2}$, Saifullah Awan ${ }^{1}$ \\ ${ }^{1}$ Department of Electrical Engineering, College of Electrical and Mechanical Engineering, \\ National University of Sciences and Technology, Islamabad, Pakistan. \\ ${ }^{2}$ National Institute of Lasers and Optronics, Islamabad, Pakistan.
}

\begin{abstract}
Pure and $\mathrm{Fe}^{+3}$ doped titanium dioxide thin films were prepared by sol-gel spin coating technique. Phase analysis, crystallite size, dislocation density and toughness of films were scrutinized by $X$-ray diffraction (XRD). The principal phase in the films was anatase. Crystallite size plummeted from 39.3 to $33.22 \mathrm{~nm}$ whereas dislocation densities escalated from $6.47 \times 10^{-4}$ to $9.06 \times 10^{-4}(\mathrm{~nm})^{-3}$ when $\mathrm{Fe}^{+3}$ content rose from 0 to $10 \%$. These mushroomed dislocation densities imparted strength to the films on account of grain boundary strengthening phenomenon. Principal anatase phase of the films was validated by Raman spectroscopy. Minor peak broadening and peak shifting was observed for doped films, that were attributed to the dislocation induced stresses by the rising $\mathrm{Fe}^{+3}$ content. UV-Vis spectrophotometry was undertaken to ascertain the transmittance of films in ultraviolet and visible spectrums. The films exhibited substantial transmittance in the visible region but there was a vivid landslide from 78 to $37 \%$ with elevation of $\mathrm{Fe}^{+3}$ content. In order to establish the band gap reduction in doped films, Tauc plot was utilized. Band gap abated from 3.24 to $3.08 \mathrm{~V}$ with burgeoning $\mathrm{Fe}^{+3}$ content from 0 to $10 \%$ so that effective photocatalytic activity can occur in the visible spectrum as well.
\end{abstract}

Keywords- $\mathrm{Fe}^{+3}$ doped, Anatase, Crystallite size, Dislocation density, Band gap, Tauc plot, Photocatalytic

\section{Introduction}

Titanium dioxide $\left(\mathrm{TiO}_{2}\right)$ is a distinguished n-type metal oxide semiconductor with loads of wide ranging beneficial properties that can be exploited to serve the various facets of human life. $\mathrm{TiO}_{2}$ has received great attention since the last two decades owing to its high refractive index, large dielectric constant, immense physio-chemical stability, colossal inertness in austere ambiences, reduced toxicity, low cost and hassle free developmental methods. Presently, $\mathrm{TiO}_{2}$ is actively employed in optoelectronic sensors [1], waveguides [2], photovoltaic cells [3], photo catalysts [4], as pigments in paints [5] and food (for colouring and additives), biomaterials (as bone substituents and cardiovascular implants) [6] and neutralizing agent against microbial organisms [7].

\section{Authors Names \& Affiliation}

Asfandyar Imtiaz

National University of Sciences \& Technology, Pakistan.

Attaullah Shah

National Institute of Lasers \& Optronics, Pakistan.
$\mathrm{TiO}_{2}$, being a remarkable photocatalyst in UV region, lacks photophysical properties in visible region due to its large bandgap $(3.25 \mathrm{eV})$. UV constitutes round about $5 \%$ of the solar spectrum and this constraint curtails its effectiveness, thus rendering merely $1 \%$ solar energy conversion. Moreover, the photogenerated electron hole pairs exhibit tremendously high recombination time, consequently further marring its reliability as photocatalyst. Hence, much research has been directed to redress these problems. Researchers have endeavoured to reduce the band gap by doping and surface decoration. Others embarked on the mission to reduce the recombination time by altering the size and shape of crystallites and incorporating charge traps and forbidden energy levels in the band gap region. Variety of methods have been proposed and implemented to successfully incorporate dopants within $\mathrm{TiO}_{2}$ like anodization, chemical vapor deposition, sputtering, and plasma spraying [8]. The downside of aforementioned techniques is that they are hugely expensive and require scrupulous care to acquire the targeted objectives. Therefore, sol-gel approach provides an easy way out as it's straightforward and cost effective at the same time [9].

In this paper, structural and optical features of iron $\left(\mathrm{Fe}^{+3}\right)$ doped $\mathrm{TiO}_{2}$ thin films prepared by sol-gel method have been rigorously analyzed. The crystal structure and different phase presence were studied through X-ray diffraction (XRD). Vibration modes were probed through Raman spectroscopy to acquire the finger print of the thin films grown. Transmittance and band gap variations were investigated through spectrophotometry.

\section{Experimental work}

The sol gel technique entails hydrolysis of metal alkoxides in alcoholic medium in the presence of acid catalyst. The acid works as chelating agent at the same time thus ensuring stability of the structure. In this study, ethanol $\left(\mathrm{C}_{2} \mathrm{H}_{5} \mathrm{OH}\right)$ was utilized as alcoholic solvent. Acetic acid $\left(\mathrm{CH}_{3} \mathrm{COOH}\right)$ performed the role of chelating agent and the metal alkoxide employed was titanium isopropoxide (TIP) $\mathrm{Ti}\left\{\mathrm{OCH}\left(\mathrm{CH}_{3}\right)_{2}\right\}_{4}$. $0.12 \mathrm{M}$ solution of $11.40 \mathrm{ml}$ of $\mathrm{Ti}$ was made. The technique involves taking $10 \mathrm{ml}$ of ethanol and mixing it with $1 \mathrm{ml}$ of acetic acid and the mixture is stirred for 20 minutes on magnetic stirrer. Afterwards, $0.40 \mathrm{ml}$ of TIP in introduced drop wise slowly into the mixture while stirring. Now, stirring is carried out for an hour. That is the recipe for pure $\mathrm{TiO}_{2}$.

For the case of $\mathrm{Fe}^{+3}$ doped $\mathrm{TiO}_{2}$, previous steps are implemented initially, followed by introduction of anhydrous iron nitrate $\left(\mathrm{Fe}\left(\mathrm{NO}_{3}\right)_{3}\right)$ which serves as precursor of $\mathrm{Fe}^{+3}$. This step requires massive stirring. Subsequently, the stirring is carried out for 24 hours to ensure thorough mixing. Eventually, we end up with neat transparent 
Proc. of the Sixth International Conference on Advances in Computing, Electronics and Communication - ACEC 2017. Copyright (C) Institute of Research Engineers and Doctors. All rights reserved.

ISBN: 978-1-63248-138-2 doi: 10.15224/ 978-1-63248-138-2-07

yellowish solution. Three types of solutions were made having $4 \%, 7 \%$ and $10 \% \mathrm{Fe}^{+3}$ content. Lastly, the pure and doped $\mathrm{Fe}: \mathrm{TiO}_{2}$ solutions were spin coated on the glass substrates. Dopant amounts corresponding to percentages in Table 1 were determined using mole and molar mass relations.

TABLE 1 DOPANT PERCENTAGES OF Fe \& CORRESPONDING MASSES OF $\mathrm{Fe}\left(\mathrm{NO}_{3}\right)_{3}$

\begin{tabular}{|c|c|}
\hline$\% \mathbf{F e}$ & Mass of $\mathbf{F e}\left(\mathbf{N O}_{\mathbf{3}}\right)_{\mathbf{3}}(\mathbf{m g})$ \\
\hline 4 & 13.25 \\
\hline 7 & 23.19 \\
\hline 10 & 33.13 \\
\hline
\end{tabular}

Growth of the thin films was carried out through spin coating by adjusting the parameters with utmost care. The spin coating was done at $3000 \mathrm{rpm}$ for 30 s followed by drying on hot plate for 15 minutes. After a gap of 2 minutes, which allows cooling of the previously deposited coating, the sample is given another re-run. Each sample is passed through a total of 8 cycles to ensure thick film deposition. The whole experiment is implemented in room temperature ambience. Lastly, the samples were annealed at $450^{\circ} \mathrm{C}$ for 30 minutes to smoothen and homogenize the depositions. The thickness of deposited films was found to be in the range of $160 \mathrm{~nm}$ through ellipsometric studies. The spectroscopic ellipsometer used was of Sentech Instruments GmbH. The Figure 1 precisely delineates the experimental method employed to achieve homogeneous and smooth thin films of pure and doped $\left(\mathrm{Fe}^{+3}\right)$ titanium dioxide.

\section{Results \& Discussions}

The following characterization techniques were utilized to unravel the structural and optical properties of the films.

\section{A. X-ray Diffraction Measurements}

$\mathrm{X}$-ray diffraction patterns of pure and doped $(4 \%, 7 \%$ and $10 \%) \mathrm{Fe}: \mathrm{TiO}_{2}$ thin films deposited on glass substrates as shown in Figure 2. X-ray analysis was done through Bruker $\mathrm{D} 8$ diffractometer using $\mathrm{Cu}-\mathrm{K} \alpha$ radiation $(0.1540 \mathrm{~nm})$. The diffractogram exhibits multi-phase presence of anatase, brookite and rutile but most of the peaks belonging to anatase family, corroborate that the films deposited were predominantly anatase in nature.

Certain peaks at $2 \theta=31.18^{\circ}$ and $44.96^{\circ}$ indicate the minor presence of brookite and rutile phases respectively in all the patterns. Other peaks at $25.35^{\circ}, 37.95^{\circ}, 48.07^{\circ}$, $54.04^{\circ}, 56.01^{\circ}$ and $74.85^{\circ}$ reveal (101), (004), (200), (105), (211) and (215) planes respectively, thereby validating prevalent anatase phase of the material (JCPDS Card No.211272).

All of these are principal diffraction planes. These planes have the maximum density, that's why they pose colossal hindrance to the incident x-rays. Additionally, these planes also lie on the Ewald's sphere. There is a bleak representation of $\mathrm{Ti}_{4} \mathrm{O}_{7}$ as well depicting (202) plane at $28.93^{\circ}$ which subsides in higher doping amounts. The hump is indicative of the amorphous nature of glass substrate.

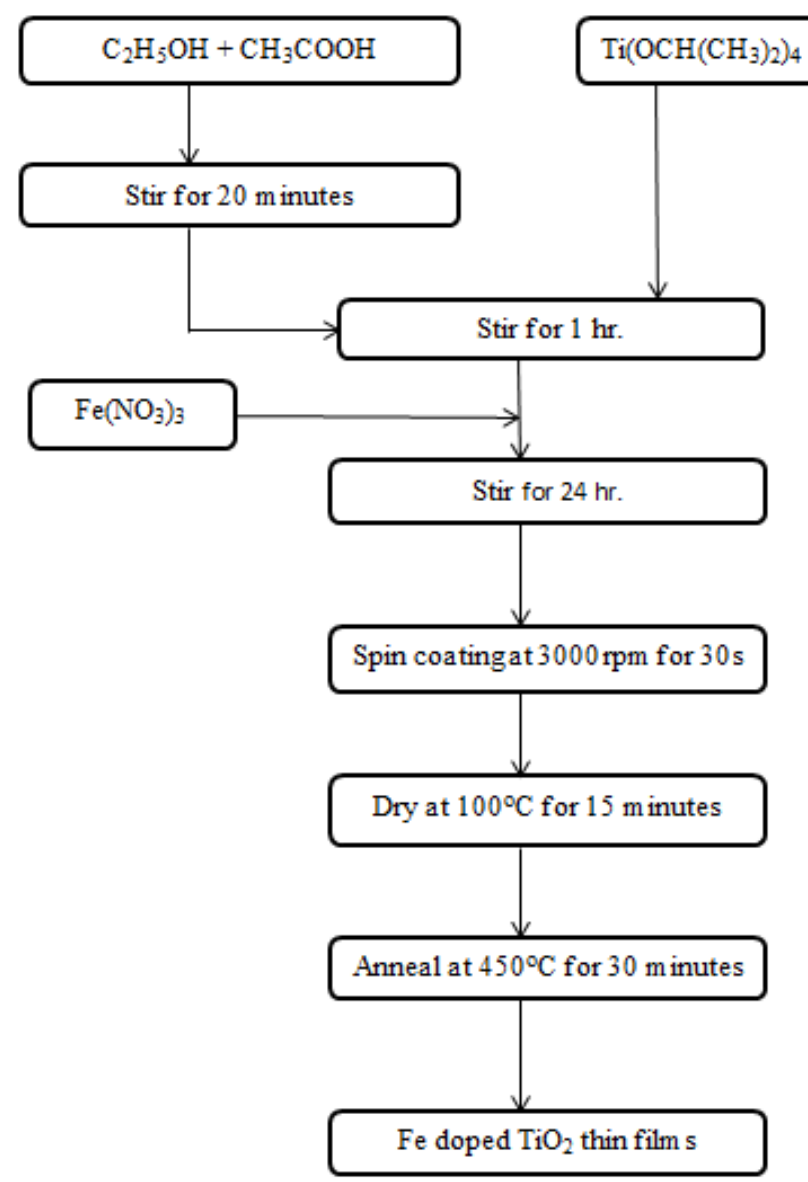

Figure 1. Schematic approach of the methodology followed

The average crystallite size was probed through DebyeScherrer relation which is largely dependent on full width at half maximum (FWHM) variartions.

$$
\mathrm{D}=\frac{\mathrm{K} \lambda}{\beta \cos \theta}
$$

Where, $\mathrm{K}$ is a constant, whose value is largely contingent on the geometry of crystallites. For spherical crystallites, $\mathrm{K}$ is equal to $0.9 . \lambda$ is the $\mathrm{X}$-ray wavelength in $\mathrm{nm}$, having $0.1540 \mathrm{~nm}$ value. $\beta$ is FWHM of a peak in radians. $\Theta$ represents Bragg's angle in radians. There is another promising feature that there is no phase appearance of iron in the patterns whatsoever. There could be two conceivable explanations to that. One, the $\mathrm{Fe}^{+3}$ content in $\mathrm{Fe}: \mathrm{TiO}_{2}$ films is below the XRD detection threshold, other being the similar size of $\mathrm{Ti}^{+4}\left(0.68 \mathrm{~A}^{\mathrm{o}}\right)$ and $\mathrm{Fe}^{+3}\left(0.64 \mathrm{~A}^{\circ}\right)$ such that $\mathrm{Fe}^{+3}$ is exquisitely and thoroughly incorporated into the host lattice [10]. The values of crystallites are given in Table 2. The results are very gratifying. There is a progressive decrease in the crystallite size with increase in dopant amounts. This diminishing pattern causes peak broadening. The general trend is that the peak intensities are steadily lessening with increasing dopant concentration, as a consequence of which, the crystallization is deteriorating rapidly.

Dislocation density is another cardinal factor giving insight into crystal hardness. Trapping centres, crystallographic defects and other such inconsistencies within the lattice engender dislocations. It gives 
Proc. of the Sixth International Conference on Advances in Computing, Electronics and Communication - ACEC 2017. Copyright (C) Institute of Research Engineers and Doctors. All rights reserved.

ISBN: 978-1-63248-138-2 doi: 10.15224/ 978-1-63248-138-2-07

enlightenment regarding the strength of materials. Strength of a material depends on its propensity to successfully restrict the motion of dislocations

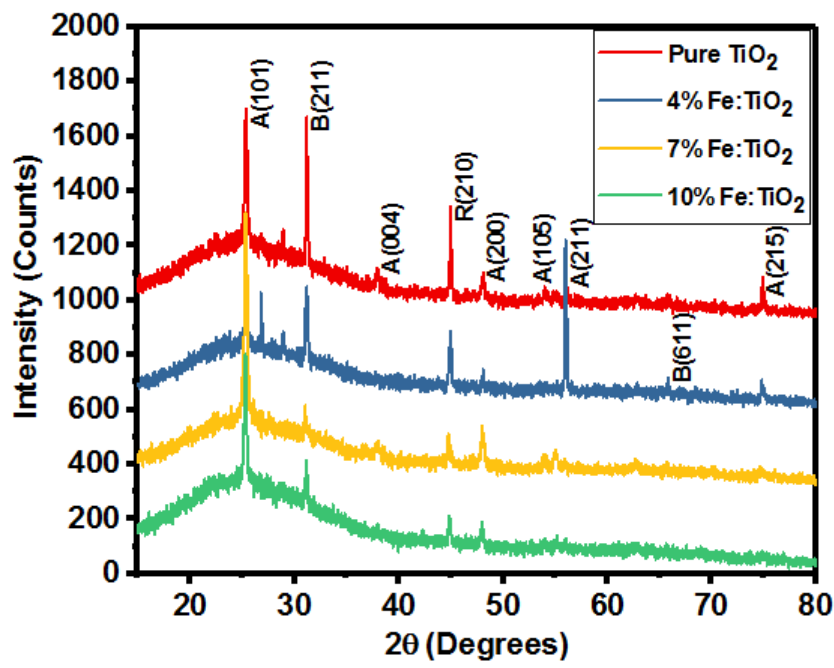

Figure 2. XRD of variably doped $\mathrm{TiO}_{2}$ thin films

Dislocation density is governed by the following two equations [11],

$$
\begin{gathered}
\delta=\frac{15 \beta \cos \theta}{4 \mathrm{aD}} \\
\delta=\frac{1}{\mathrm{D}^{2}}
\end{gathered}
$$

Where, $\delta$ is dislocation density in $(\mathrm{nm})^{-3}, \beta$ is FWHM in radians, $\theta$ is Bragg's angle in radians, a is lattice constant in $\mathrm{nm}$ and $\mathrm{D}$ is crystallite size in $\mathrm{nm}$. Both the equations render equally accurate results. The dislocation densities calculated are enlisted in Table 2. As grain size is decreasing with increasing dopant concentration, dislocation densities are rising symmetrically which ultimately imparts strength to smaller grain size materials. The mechanism of grain size reduction relies on grain boundaries to provide this constraint. These dislocations are blocked at the grain boundary. They pile up, creating a driving force which pushes them towards the nearby grains. The bigger the grain, the larger the pile up and larger will be the driving pull, therefore requiring less stress to push the dislocations into the next grain. Contrary to that, smaller grains have smaller pile up and driving force, thus needing colossal stress to initiate the propagation phenomenon of dislocations. Thus smaller grains with massive amount of trapped dislocations render higher yield strength. Hence, $10 \% \mathrm{Fe}: \mathrm{TiO}_{2}$ films having smallest crystallite size exhibit greater toughness whereas pure $\mathrm{TiO}_{2}$ films are the weakest which is ascribed to their largest crystallite size.

\section{B. Raman Spectroscopy}

Raman spectra of pure and doped $\mathrm{TiO}_{2}$ samples are presented in Figure 3. Here, the peaks are illustrating the various vibrational modes present in the sample. Actually, anatase engenders six Raman active modes in vibration spectra: 3 corresponding to $\operatorname{Eg}\left(144,197\right.$ and $\left.638 \mathrm{~cm}^{-1}\right), 2$ corresponding to $\mathrm{B}_{1 \mathrm{~g}}\left(399\right.$ and $\left.519 \mathrm{~cm}^{-1}\right)$ and one corresponding to $\mathrm{A}_{1 \mathrm{~g}}\left(513 \mathrm{~cm}^{-1}\right)$ [12]. One thing is worth mentioning is that only those vibrational modes can be scrutinized which follow selection rules constraint.

\section{TABLE 2. DOPING VARAIATION IMPACT ON CRYSTALLITE} SIZE \& DISLOCATION DENSITY

\begin{tabular}{|c|c|c|}
\hline Films & $\begin{array}{c}\text { Crystallite } \\
\text { size (nm) }\end{array}$ & $\begin{array}{c}\text { Dislocation } \\
\text { Density (nm) } \\
\mathbf{1 0}^{-\mathbf{3}} \mathbf{x}\end{array}$ \\
\hline Pure $\mathrm{TiO}_{2}$ & 39.3 & 6.47 \\
\hline $4 \% \mathrm{Fe}: \mathrm{TiO}_{2}$ & 36.97 & 7.31 \\
\hline $7 \% \mathrm{Fe}: \mathrm{TiO}_{2}$ & 35.33 & 8.01 \\
\hline $10 \% \mathrm{Fe}: \mathrm{TiO}_{2}$ & 33.22 & 9.06 \\
\hline
\end{tabular}

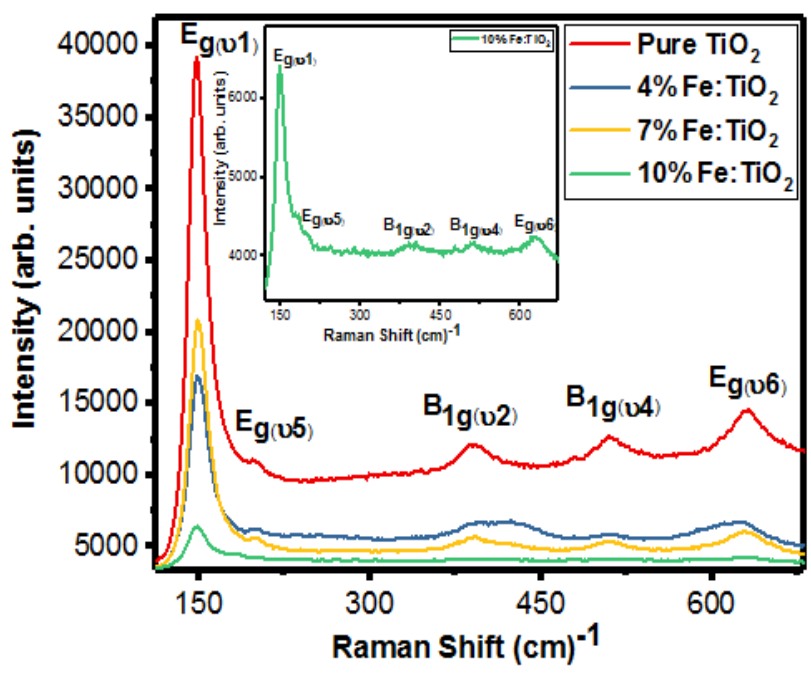

Figure 3. Raman spectra of $\mathrm{Fe}: \mathrm{TiO}_{2}$ films

In this study with $325 \mathrm{~nm}$ excitation, five modes were observed at 148, 197, 392, 509 and $632 \mathrm{~cm}^{-1}$. These modes justify the preferential anatase phase in the samples. The peak at $148 \mathrm{~cm}^{-1}$ is characteristic Raman mode of anatase. $E_{g}$ mode portrays symmetric stretching vibration of O-Ti-O bond. $\mathrm{B}_{1 \mathrm{~g}}$ portrays symmetric bending vibrations of $\mathrm{O}-\mathrm{Ti}-\mathrm{O}$ bond and $\mathrm{A}_{1 \mathrm{~g}}$ is the testament to the occurrence of asymmetric bending vibrations of O-Ti-O bond [13]. All the peaks are indicating diminishing trend that is ascribable to the increasing dopant concentration that incorporate defects within the material. Slight shifting of the peaks and broadening can be attributed to stresses dominating the films.

\section{Optical Analysis}

The UV-Vis transmittance spectra acquired through spectrophotometry is plotted in Figure 4. The results show that all the films exhibit transparency of epic proportions in both the UV and visible region. The transmittance is reducing from 78 to $37 \%$ with increasing dopant concentration; also there is a red shift in the absorption edge which makes photocatalytic degradation quite convenient in the visible region as well.

This shift is on account of charge transfer transition between the d-orbital electrons of iron and the conduction or valence band of $\mathrm{TiO}_{2}$. The band gap reduction gives the right picture regarding the essence of photocatalytic activity in the visible region. 
Proc. of the Sixth International Conference on Advances in Computing, Electronics and Communication - ACEC 2017. Copyright (C) Institute of Research Engineers and Doctors. All rights reserved.

ISBN: 978-1-63248-138-2 doi: 10.15224/ 978-1-63248-138-2-07

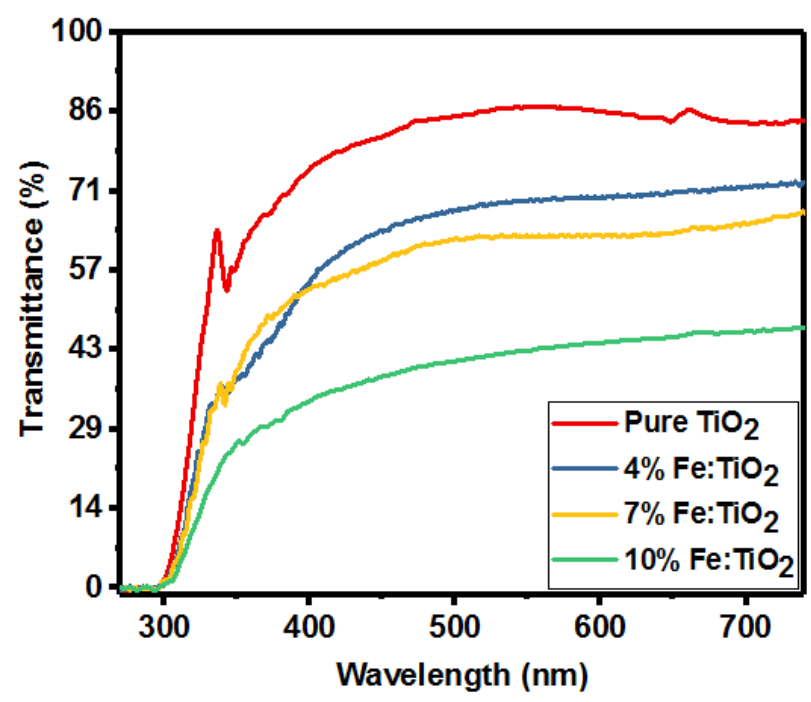

Figure 4. Transmission spectra of differently doped $\mathrm{Fe}: \mathrm{TiO}_{2}$ films

To study that effect, Tauc plot is utilized [14]. It is given by the following equation,

$$
(\alpha h v)^{\frac{1}{2}}=\mathrm{k}\left(\mathrm{hu}-\mathrm{E}_{\mathrm{g}}\right)
$$

Where, hv is photon energy in $\mathrm{eV}, \mathrm{k}$ is constant and $\alpha$ is optical absorption coefficient given in units of $\mathrm{cm}^{-1} \mathrm{eV}$. The optical absorption coefficient is given as,

$$
\alpha=\frac{1}{\mathrm{~d}} \ln \frac{1}{\mathrm{~T}}
$$

Where $\mathrm{T}$ is the transmittance at each wavelength and $\mathrm{d}$ is the thickness of film, which in this study is found out through ellipsometry having value of $160 \mathrm{~nm}$. Actually, it is $(\alpha h v)^{1 / r}$, but for indirect band gap semiconductors like anatase $r=2$. The tauc plot plotted between $(\alpha h v)^{1 / 2}$ and hv is shown in Figure 5. The linear region of the graph is extrapolated to $\mathrm{x}$ axis which yields the optical band gap of the material. The bandgap variation with doping is enlisted in Table 3. It reaffirms bandgap reduction with rise of $\mathrm{Fe}^{+3}$ content [15].

TABLE 3. OPTICAL BANDGAP VARIATION WITH DOPING PERCENTAGE

\begin{tabular}{|c|c|}
\hline Doping (\%) & Optical Bandgap (eV) \\
\hline Pure $\mathrm{TiO}_{2}$ & 3.24 \\
\hline $4 \% \mathrm{Fe}^{+3}$ & 3.18 \\
\hline $7 \% \mathrm{Fe}^{+3}$ & 3.13 \\
\hline $10 \% \mathrm{Fe}^{+3}$ & 3.08 \\
\hline
\end{tabular}

Actually, iron tends to incorporate shallow donor and acceptor levels into the bandgap. These levels serve as charge trapping sites to dilate the recombination time and transport the carriers to the surface to be available for surface reactions.
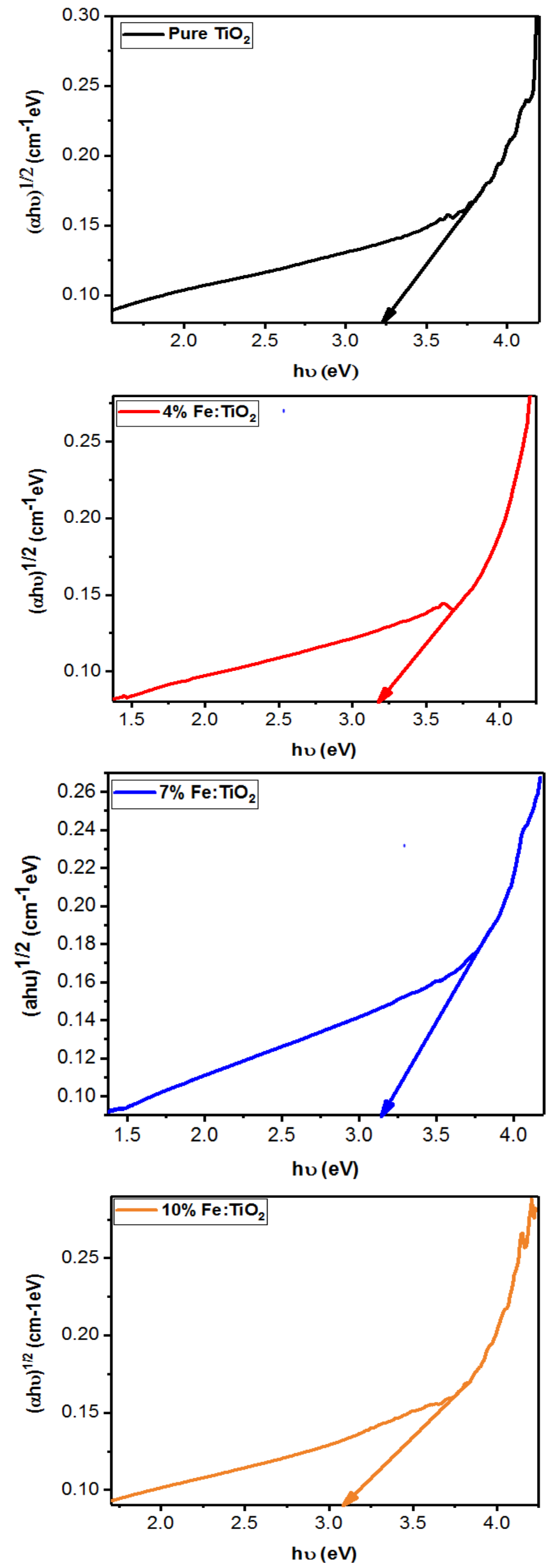

Figure 5. Bandgaps of $\mathrm{Fe}: \mathrm{TiO}_{2}$ films 
Proc. of the Sixth International Conference on Advances in Computing, Electronics and Communication - ACEC 2017. Copyright (C) Institute of Research Engineers and Doctors. All rights reserved.

ISBN: 978-1-63248-138-2 doi: 10.15224/ 978-1-63248-138-2-07

\section{Conclusion}

The structural and optical properties of pure and $\mathrm{Fe}^{+3}$ doped titanium dioxide thin films were extensively probed through X-ray diffraction, Raman spectroscopy and UV-Vis spectrophotometry. XRD analysis revealed the presence of predominant anatase phase along with minor representation of rutile and brookite phases. There was progressive decline in the crystallite size from 39.3 to 33.22 $\mathrm{nm}$ with increasing $\mathrm{Fe}^{+3}$ content. The dislocation densities enhanced from $6.47 \times 10^{-4}$ to $9.06 \times 10^{-4}(\mathrm{~nm})^{-3}$. That reduced crystallite size was instrumental in soaring up the dislocation density, thereby imparting significant strength and toughness to the doped thin films in comparison to their pure $\mathrm{TiO}_{2}$ counterpart. There was no spurious iron content found in the XRD pattern. Raman analysis further endorsed the predominant existence of anatase phase. Broadening and slight shifting of the peaks gave insight into the microstrains present inside the films. Transmittance of all the films in the visible region was amazing especially the pure $\mathrm{TiO}_{2}$. Abating trend of transmittance with uptick of iron content was pretty evident and red shift in the absorption edge was observed. Bandgap shrinked from $3.24 \mathrm{eV}$ to $3.08 \mathrm{eV}$, thereby catering for the photocatalytic effect in the visible spectrum.

\section{References}

[1] Janitabar-Darzi, S., Mahjoub, A. and Nilchi, A., "Investigation of structural, optical and photocatalytic properties of mesoporous $\mathrm{TiO}_{2}$ thin film synthesized by sol-gel templating technique," Physica E: Low-dimensional Systems and Nanostructures, 42(2), pp.176-181, 2009.

[2] Mechiakh, R., Meriche, F., Kremer, R., Bensaha, R., Boudine, B. and Boudrioua, A., " $\mathrm{TiO}_{2}$ thin films prepared by sol-gel method for waveguiding applications: Correlation between the structural and optical properties." Optical Materials, 30(4), pp.645-651, 2007.

[3] Bai, Y., Mora-Seró, I., De Angelis, F., Bisquert, J. and Wang, P., "Titanium Dioxide Nanomaterials for Photovoltaic Applications." Chemical Reviews, 114(19), pp.10095-10130, 2014.

[4] Kato, K., Tsuzuki, A., Taoda, H., Torii, Y., Kato, T. and Butsugan, Y., "Crystal structures of $\mathrm{TiO}_{2}$ thin coatings prepared from the alkoxide solution via the dip-coating technique affecting the photocatalytic decomposition of aqueous acetic acid." Journal of Materials Science, 29(22), pp.5911-5915, 1994.

[5] Diebold, M., "TiO 2 Pigments in Liquid Paints." Application of Light Scattering to Coatings, pp.83-109. 2014

[6] Cui, C., Liu, H., Li, Y., Sun, J., Wang, R., Liu, S. and Lindsay Greer, A., "Fabrication and biocompatibility of nano- $\mathrm{TiO}_{2} /$ titanium alloys biomaterials." Materials Letters, 59(24-25), pp.3144-3148, 2005.

[7] Kubacka, A., Diez, M., Rojo, D., Bargiela, R., Ciordia, S., Zapico, I., Albar, J., Barbas, C., Martins dos Santos, V., Fernández-García, M. and Ferrer, M., "Understanding the antimicrobial mechanism of $\mathrm{TiO}_{2}$ based nanocomposite films in a pathogenic bacterium." Scientific Reports, 4(1), 2014

[8] FUJISHIMA, A. and HONDA, K., "Electrochemical Photolysis of Water at a Semiconductor Electrode." Nature, 238(5358), pp.37-38, 1972.

[9] López, T., Rojas, F., Alexander-Katz, R., Galindo, F., Balankin, A. and Buljan, A., "Porosity, structural and fractal study of sol-gel $\mathrm{TiO}_{2}$ $\mathrm{CeO}_{2}$ mixed oxides." Journal of Solid State Chemistry, 177(6), pp.1873-1885, 2004.

[10] Zhou, M., Yu, J. and Cheng, B., "Effects of Fe-doping on the photocatalytic activity of mesoporous $\mathrm{TiO}_{2}$ powders prepared by an ultrasonic method." Journal of Hazardous Materials, 137(3), pp.18381847,2006

[11] Subbaiah, Y., Prathap, P. and Reddy, K., "Structural, electrical and optical properties of $\mathrm{ZnS}$ films deposited by close-spaced evaporation.” Applied Surface Science, 253(5), pp.2409-2415, 2006.
[12] Antony, R., Dasgupta, A., Mahana, S., Topwal, D., Mathews, T. and Dhara, S., "Resonance Raman spectroscopic study for radial vibrational modes in ultra-thin walled $\mathrm{TiO}_{2}$ nanotubes." Journal of Raman Spectroscopy, 46(2), pp.231-235, 2015.

[13] Yan, J., Wu, G., Guan, N., Li, L., Li, Z. and Cao, X., "Understanding the effect of surface/bulk defects on the photocatalytic activity of $\mathrm{TiO}_{2}$ : anatase versus rutile." Physical Chemistry Chemical Physics, 15(26), p.10978, 2013.

[14] Bennaceur, J., Mechiakh, R., Bousbih, F., Jaouadi, M. and Chtourou, R., "Effect of annealing temperatures and of high content of the iron ion $\left(\mathrm{Fe}^{3+}\right)$-doping on transition anatase-rutile phase of nanocrystalline $\mathrm{TiO}_{2}$ thin films prepared by sol-gel spin coating." Journal of Sol-Gel Science and Technology, 61(1), pp.69-76, 2011.

[15] Radecka, M., Pasierb, P., Zakrzewska, K. and Rękas, M., "Transport properties of $(\mathrm{Sn}, \mathrm{Ti}) \mathrm{O}_{2}$ polycrystalline ceramics and thin films." Solid State Ionics, 119(1-4), pp.43-48, 1999.

About Authors:

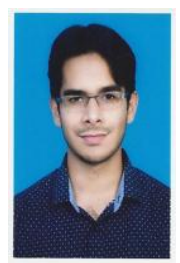

Asfandyar Imtiaz got his BE Electrical Engineering degree from College of Electrical and Mechanical Engineering, NUST. He is currently pursuing his Masters in Electrical Engineering from College of Electrical and Mechanical Engineering, NUST . His research interests are thin film, photonics, optics and optronics.

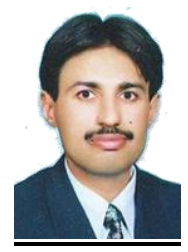

Mashhood Ahmad received his Ph.D. degree from Quaid-i-Azam University, Islamabad in quantum optics. He worked on quantum state measurement schemes and entanglement dynamics. Currently, he is in the faculty of Department of Electrical Engineering, College of Electrical Engineering, National University of Sciences and Technology, Islamabad, Pakistan.

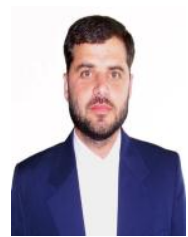

Attaullah Shah received his Ph.D. degree from PIEAS University, Islamabad. He is currently serving as Principal Scientist at National Institute of Lasers and Optronics, Islamabad. His research interests include $\mathrm{GaN}$ based devices and structures.

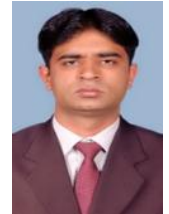

Saifullah Awan got his Ph.D. degree in Physics from Quaid-i-Azam University, Islamabad. His specialization is semiconductor and magnetic nanomaterials. He is currently serving as Assistant Professor at National University of Sciences \& Technology. 